\title{
Fluorescent CXCR4 chemokine receptor antagonists: metal activated binding $\dagger$
}

\author{
Abid Khan, ${ }^{a}$ Jon D. Silversides, ${ }^{a}$ Leigh Madden, ${ }^{b}$ John Greenman ${ }^{b}$ and Stephen J. Archibald ${ }^{a}$ \\ Received (in Cambridge, UK) 6th October 2006, Accepted 15th November 2006 \\ First published as an Advance Article on the web 4th December 2006 \\ DOI: 10.1039/b614557d
}

The copper(II) complex of a novel rhodamine-azamacrocycle conjugate binds to the CXCR4 chemokine receptor and competes effectively against anti-CXCR4 monoclonal antibodies. The copper macrocycle unit adopts a trans-II configuration in the solid state.

Research into immunotherapeutic drugs based around cytokines, chemokines and growth factors is a rapidly developing and expanding area. ${ }^{1-4}$ The chemokine and chemokine receptor family is generally accepted to have recently reached completion with the discovery of 18 chemokine receptors and 46 chemokines. ${ }^{2}$ Now the challenge is to use this information to develop novel therapeutic drugs and diagnostic applications.

The CXCR4 chemokine receptor is a seven transmembrane G-protein coupled receptor with multiple critical functions in both the normal and pathological states, ${ }^{5,6}$ having a sole natural ligand (CXCL12). Synthetic small molecule antagonists exist, including a xylyl bridged bicyclam AMD3100, ${ }^{7}$ which have been shown to have both a high binding specificity and an effective inhibitory action against a number of disease states including arthritis, cancer and HIV infection. ${ }^{8-10}$ AMD3100 is currently in clinical trials for stem cell mobilisation (Mozobil). ${ }^{11}$

In this work we aim to produce a fluorescently labeled small molecule that selectively binds to a chemokine receptor. Such compounds could be used for in vitro diagnostic assays and competition binding studies in drug development. Our approach has been to design configurationally restricted cyclam-based metal complexes as CXCR4 antagonists. ${ }^{12}$ This locks the configuration of the complex and optimises the metal coordination environment for interaction with an aspartate residue on receptor binding. We present the synthesis of a novel ethylene bridged cyclam-based bifunctional chelator, the X-ray structure of a related copper complex and the binding assays of the rhodamine conjugates in competition with anti-CXCR4 monoclonal antibodies.

The piperazine-containing macrocycle was synthesized from a bis-aminal unit (Scheme 1). $\uparrow$ The use of glyoxal bridged cyclam allows for a high yielding mono-functionalisation reaction with a benzyl halide due to the selective reactivity of the nitrogen nucleophiles. ${ }^{13-15}$ The bis-aminal can then be reduced to give a

${ }^{a}$ Department of Chemistry and Institute of Clinical Biosciences, The

University of Hull, Cottingham Road, Hull, UK HU6 7RX.

E-mail: s.j.archibald@hull.ac.uk; Fax: +44(0)1482466410;

Tel: +44(0) 1482465488

${ }^{b}$ Medical Research Laboratory and Institute of Clinical Biosciences, The University of Hull, Cottingham Road, Hull, UK HU6 7RX

$\dagger$ Electronic supplementary information (ESI) available: Experimental procedures (microbiology and chemical synthesis), fluorescence emission spectra and X-ray crystallographic data. See DOI: 10.1039/b614557d mono- $N$-benzylated cyclam macrocycle with an additional ethylene bridge between adjacent nitrogen positions. ${ }^{16}$ The 4-nitrobenzyl derivative was produced and could selectively be reduced to the amine in high yields with no cleavage of the benzylic unit using $\mathrm{H}_{2}$ and poisoned $\mathrm{Pd} / \mathrm{CaCO}_{3}$. Reaction of the benzylamine macrocycle, $\mathbf{4}$, with rhodamine isothiocyanate (RITC) gave $\mathbf{5}$ in high yield. Copper complexation was carried out in methanol to give the metallated form of the antagonist, $\mathrm{Cu} 5 \mathrm{Cl}_{2}$. AMD3100 contains two macrocyclic rings which both contribute to the binding interaction. Our new compound is mono-macrocyclic, but we aim to sufficiently optimise binding through configurational restriction and inclusion of a metal ion. There are other examples of mono-macrocyclic CXCR4 antagonists. ${ }^{17}$

For this type of molecule, binding to the chemokine receptor is thought to occur via aspartate residues on the extracellular loops and outer surface. ${ }^{18}$ The receptor has an overall surface charge of 9- and may interact with the protonated free macrocycle via H-bonding. The copper(II) complex has an overall charge of $2+$ and the additional potential for a coordination interaction between the copper ion and a carboxylate from an aspartate residue (on exchange of the bound chloride). Aspartate residues 171 and 262 have been shown to interact with AMD3100 using site-directed mutagenesis studies. ${ }^{18}$ Previous data suggest that the presence of the metal ion will significantly enhance binding to the CXCR4 receptor over the free macrocycle. ${ }^{19}$

Configuration of the cyclam rings in metal complexes AMD3100 is of key importance to the binding interaction. ${ }^{20,21}$ To confirm the configuration of the macrocycle in our bridged analogue, the structure of an analogous copper(II) complex, $[\mathrm{Cu} 6 \mathrm{Cl}]\left(\mathrm{CuCl}_{2}\right)$ with the benzyl-armed bridged macrocycle, was determined by X-ray crystallography (Fig. 1)\$ Upon complexation to a copper(II) ion, the macrocycle adopts a trans-II configuration with the piperazine ring in the boat conformation. ${ }^{22}$ The copper complex has a distorted square-based pyramidal geometry with the four nitrogen donors from the macrocyclic ligand and an axially coordinated chloride ion. The $\mathrm{Cu}-\mathrm{N}$ bond distances are in the range 1.996(3)-2.072(4) $\AA$, and the $\mathrm{Cu}-\mathrm{Cl}$ bond length is 2.491(11) $\AA$. The counter anion is $\left[\mathrm{CuCl}_{2}\right]^{-}$, formed by reduction of the copper salt $\mathrm{CuCl}_{2} \cdot 2 \mathrm{H}_{2} \mathrm{O}$ during the complexation of the metal centre to the macrocycle.

Paramagnetic metal ions affect the fluorescence properties of their ligands ${ }^{23}$ and fluorescence quenching has been used to detect copper(II) ions. ${ }^{24}$ The magnitude of the effect is expected to be reduced by an increased distance between the fluorophore and the chelated metal ion. Significant quenching of the fluorescence (approx. 75\%) was observed on formation of $\mathrm{Cu}_{5} \mathrm{Cl}_{2}$; however, the fluorescence emission was still sufficient to detect the compound in 


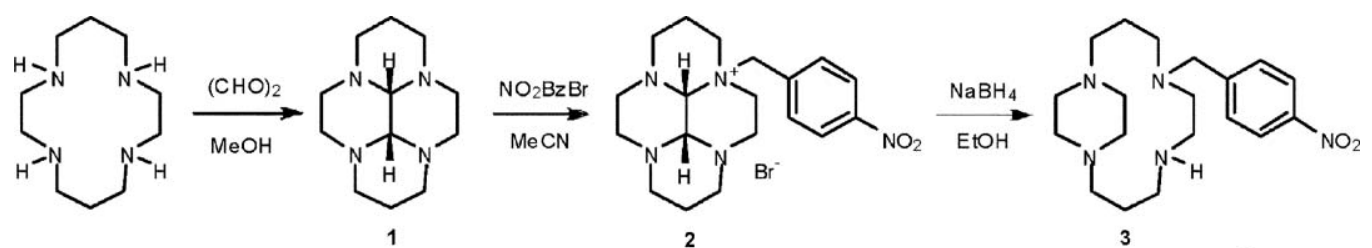

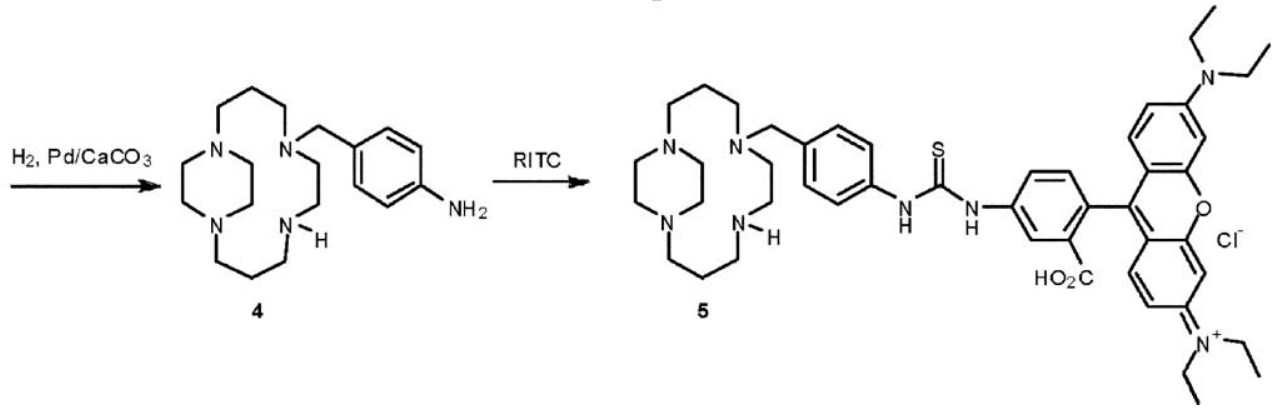

Scheme 1 Synthesis of the mono-functionalised piperazino macrocycle and rhodamine attachment to the 4-amino benzyl derivative.
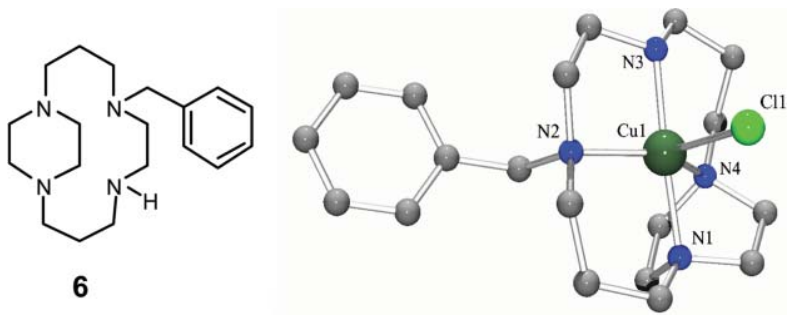

Fig. 1 Ball and stick representation of the X-ray crystal structure of the copper(II) complex formed with the benzyl derivative of the piperazine tetra-aza macrocycle. $\mathrm{H}$-atoms and the $\left[\mathrm{CuCl}_{2}\right]^{-}$counter anion have been omitted for clarity.

biological systems. $\dagger$ Complex stability is also important. The copper(II) complex of a related piperazino cyclam macrocycle has been studied by Fabbrizzi and co-workers and shown to have a demetallation half life of $>20$ days in $1 \mathrm{M} \mathrm{HClO}_{4} \cdot{ }^{25}$

Cellular binding assays were carried out to determine whether the mono-macrocyclic fluorescent compounds interact with the CXCR4 chemokine receptor. A T-lymphocyte cell line (Jurkat) that expresses high levels of the CXCR4 receptor was used. Compounds 5 and $\mathrm{Cu}_{5} \mathrm{Cl}_{2}$ were analysed for binding to the Jurkat cells by flow cytometry in competition with specific anti-CXCR4 monoclonal antibodies.

Two CXCR4-specific, monoclonal antibodies were used (mAbs 44716.111 and 44717.111), both of which bind to similar regions of the extracellular loop. ${ }^{18}$ The binding assay was carried out by saturation of the receptors with a high concentration of compound (ca. $25 \mu \mathrm{M})$ followed by washing and introduction of the specific antibodies. The amount of antibody present on the cell surface was then quantified by addition of a secondary anti-mouse $\operatorname{IgG}$ fluoresceinated reagent by flow cytometry. The free macrocycle conjugate showed no shift from the positive control, suggesting that either no binding occurs or $\mathbf{5}$ is completely displaced by the antibodies [Fig. 2(A)]. The metal complex $\mathrm{Cu}_{5} \mathrm{Cl}_{2}$ binds and competes successfully with both antibodies showing a significant shift from the positive control [Fig. 2(B)].

The compounds were studied to see if any non-specific cellular uptake occurred. Rhodamine is highly lipophilic and cellular
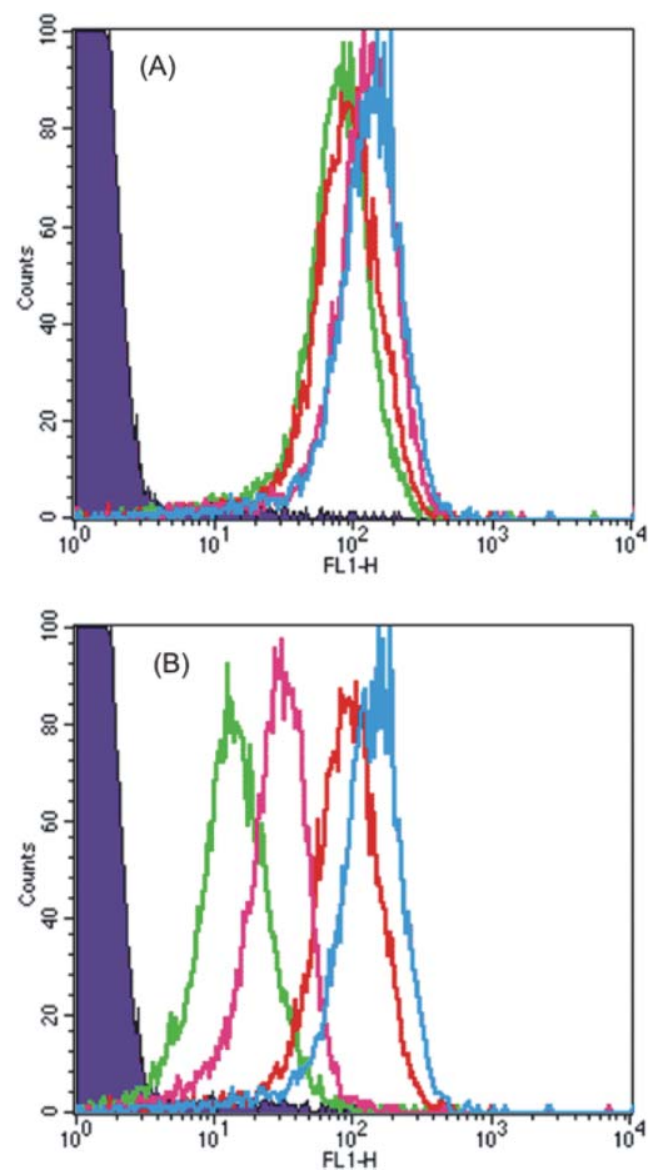

Fig. 2 Flow cytometric plot for the binding of mAbs 44716.111 (green) and 44717.111 (pink) in competition with compounds 5 (A) and $\mathrm{Cu}_{5} \mathrm{Cl}_{2}$ (B). (Negative) control (purple), (positive) controls 44716.111 (red) and 44717.111 (blue) are shown.

uptake can occur through passive diffusion and endocytosis. ${ }^{26}$ The properties of the conjugates may be dominated by the rhodamine component. Both a CXCR4 negative control cell line (Daudi) and Jurkat gave a positive fluorescent response by flow cell cytometry. Confocal microscopy studies were carried out, Fig. 3. Images 

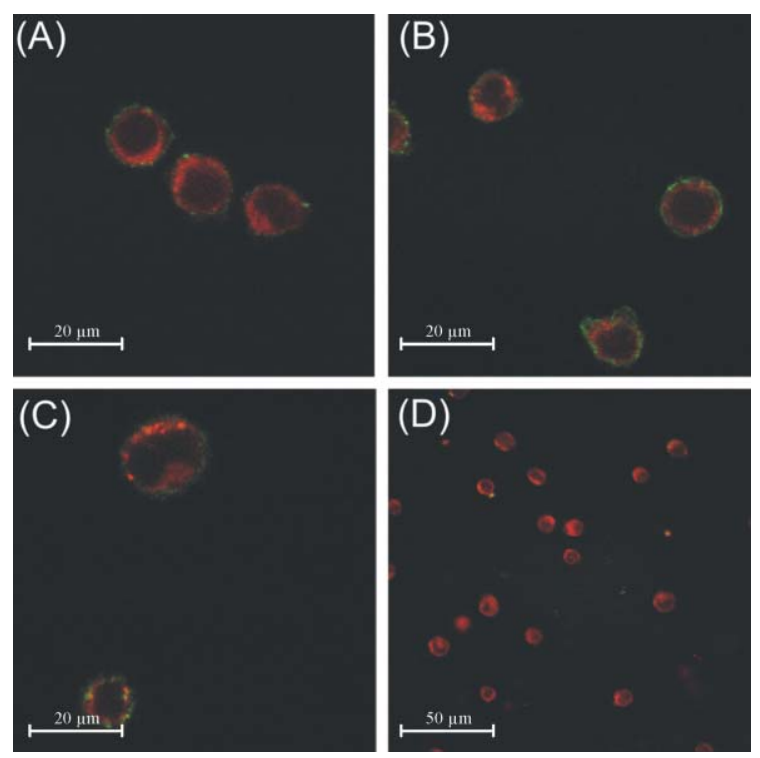

Fig. 3 Confocal images of Jurkat cells after incubation with (A) rhodamine, (B) compound 5, (C) compound $\mathrm{Cu}_{5} \mathrm{Cl}_{2}$ and (D) rhodamine after cell surface blocking. The cell surface is outlined with a CD3 FITC antibody conjugate. (The rhodamine conjugate shows up red and the FITC conjugate green.)

revealed that the rhodamine macrocycle conjugates were present in the cell cytoplasm. To determine whether the uptake of $\mathbf{5}$ and $\mathrm{Cu} 5 \mathrm{Cl}_{2}$ into the cell was via passive or active transport, cell surface blocking studies were carried out. The conjugates were still taken up into the Jurkat cells suggesting an active transport process. Modifications are required to reduce non-specific uptake. No significant cytotoxicity was observed in the course of these experiments.

It is highly significant that the metal complex competes for receptor binding more effectively than the free protonated chelator, supporting the idea that a direct coordination interaction with the receptor from the metal centre not only enhances but activates binding. Configurational restriction via an ethylene bridge offers an advantage for the metal complexes, in the presentation of only one molecular shape. ${ }^{27}$ However, it also reduces the potential for $\mathrm{H}$-bonding for the free macrocycle relative to the cyclam analogue. This could account for the inability of $\mathbf{5}$ to compete with the anti-CXCR4 antibodies in the competition binding assay.

In conclusion, we have produced a new fluorescent azamacrocyclic derivative that can bind copper(II) to form a complex with the cyclam ring in the trans-II configuration. The high yielding synthesis of these compounds exploits the selective reactivity of rigid bis-aminal intermediates. The copper(II) complex $\mathrm{Cu} 5 \mathrm{Cl}_{2}$ effectively competes with both the antibodies used in a CXCR4 binding assay. We have achieved the goal of binding a fluorescent dye to the CXCR4 chemokine receptor via a small molecule antagonist conjugate. Further research into using these fluorescent antagonists in drug screening assays and manipulation of cellular uptake properties is underway. A full investigation of the biological stability, photophysical properties and the effects of varying the metal ion will also be carried out.
Support of this work by The Wellcome Trust (Grant 069719) and the EPSRC (DTA for J. D. S.) is gratefully acknowledged. We thank the EPSRC mass spectrometry service at Swansea.

\section{Notes and references}

$\$$ Crystal data for $[\mathrm{Cu} 6 \mathrm{Cl}]\left(\mathrm{CuCl}_{2}\right): \mathrm{C}_{19} \mathrm{H}_{32} \mathrm{Cl}_{3} \mathrm{Cu}_{2} \mathrm{~N}_{4}, T=150(2) \mathrm{K}$, monoclinic, $P 2_{1} / c, a=6.8348(7), b=18.7560(14), c=17.8251(18) \AA, \beta=$ $91.838(8)^{\circ}, V=2283.9(4) \AA^{3}, Z=4, F(000)=1132,21632$ reflections measured of which 6350 were independent on $F^{2}$ with $R_{\text {int }}=0.0544$, final $R$ indices $[I>2 \sigma(I)]: R 1=0.0429, w R 2=0.1027$, final $R$ indices (all data): $R 1=0.0719, w R 2=0.1130$. Structure was solved by direct methods (SHELXS) and refined against $F^{2}$ (SHELX97) using WinGX. ${ }^{28}$ CCDC 623207. For crystallographic data in CIF or other electronic format see DOI: $10.1039 / \mathrm{b} 614557 \mathrm{~d}$.

1 L. Yan, G. M. Anderson, M. DeWitte and M. T. Nakada, Eur. J. Cancer, 2006, 42, 793-802.

2 A. E. I. Proudfoot, Nat. Rev. Immunol., 2002, 2, 106-115.

3 J. J. Onuffer and R. Horuk, Trends Pharmacol. Sci., 2002, 23, 459-467.

4 S. Ribeiro and R. Horuk, Pharmacol. Ther., 2005, 107, 44-58.

5 C. Gerard and B. J. Rollins, Nat. Immunol., 2001, 2, 108-115.

6 C. Murdoch, Immunol. Rev., 2000, 177, 175-184.

7 S. Hatse, K. Princen, G. Bridger, E. De Clercq and D. Schols, FEBS Lett., 2002, 527, 255-262.

8 T. Bourcier, T. Berbar, S. Paquet, N. Rondeau, F. Thomas, V. Borderie, L. Laroche, W. Rostene, F. Haour and A. Lombet, Mol. Vision, 2003, 9, 96-102.

9 E. De Clercq, Biochim. Biophys. Acta, 2002, 1587, 258-275.

10 P. Matthys, S. Hatse, K. Vermeire, A. Wuyts, G. Bridger, G. W. Henson, E. De Clercq, A. Billiau and D. Schols, J. Immunol., 2001, 167, 4686-4692.

11 A. Larochelle, A. Krouse, M. Metzger, D. Orlic, R. E. Donahue, S. Fricker, G. Bridger, C. E. Dunbar and P. Hematti, Blood, 2006, 107, 3772-3778.

12 G. C. Valks, G. McRobbie, E. A. Lewis, T. J. Hubin, T. M. Hunter, P. J. Sadler, C. Pannecouque, E. De Clercq and S. J. Archibald, J. Med. Chem., 2006, 49, 6162-6165.

13 E. A. Lewis, C. C. Allan, R. W. Boyle and S. J. Archibald, Tetrahedron Lett., 2004, 45, 3059-3062.

14 E. H. Wong, G. R. Weisman, D. C. Hill, D. P. Reed, M. E. Rogers, J. S. Condon, M. A. Fagan, J. C. Calabrese, K. C. Lam, I. A. Guzei and A. L. Rheingold, J. Am. Chem. Soc., 2000, 122, 10561-10 572.

15 M. Le Baccon, F. Chuburu, L. Toupet, H. Handel, M. Soibinet, I. Dechamps-Olivier, J. P. Barbiere and M. Aplincourt, New J. Chem., 2001, 25, 1168-1174.

16 R. A. Kolinski, Pol. J. Chem., 1995, 69, 1039-1045.

17 S. Hatse, K. Princen, E. De Clercq, M. M. Rosenkilde, T. W. Schwartz, P. E. Hernandez-Abad, R. T. Skerlj, G. J. Bridger and D. Schols, Biochem. Pharmacol., 2005, 70, 752-761.

18 S. Hatse, K. Princen, K. Vermeire, L. O. Gerlach, M. M. Rosenkilde, T. W. Schwartz, G. Bridger, E. De Clercq and D. Schols, FEBS Lett., 2003, 546, 300-306.

19 L. O. Gerlach, J. S. Jakobsen, K. P. Jensen, M. R. Rosenkilde, R. T. Skerlj, U. Ryde, G. J. Bridger and T. W. Schwartz, Biochemistry, 2003, 42, 710-717.

20 X. Y. Liang, J. A. Parkinson, M. Weishaupl, R. O. Gould, S. J. Paisey, H. S. Park, T. M. Hunter, C. A. Blindauer, S. Parsons and P. J. Sadler, J. Am. Chem. Soc., 2002, 124, 9105-9112.

21 X. Y. Liang, M. Weishaupl, J. A. Parkinson, S. Parsons, P. A. McGregor and P. J. Sadler, Chem.-Eur. J., 2003, 9, 4709-4717.

22 B. Bosnich, C. K. Poon and M. L. Tobe, Inorg. Chem., 1965, 4, $1102-1108$.

23 L. Fabbrizzi, F. Foti, M. Licchelli and A. Poggi, Inorg. Chem., 2002, 41, 4612-4614.

24 S. Banthia and A. Samanta, New J. Chem., 2005, 29, 1007-1010.

25 M. Boiocchi, M. Bonizzoni, L. Fabbrizzi, F. Foti, M. Licchelli, A. Poggi, A. Taglietti and M. Zema, Chem.-Eur. J., 2004, 10, 3209-3216.

26 M. S. Dordal, A. C. Ho, M. Jacksonstone, Y. F. Fu, C. L. Goolsby and J. N. Winter, Cytometry, 1995, 20, 307-314.

27 T. M. Hunter, S. J. Paisey, H. S. Park, L. Cleghorn, A. Parkin, S. Parsons and P. J. Sadler, J. Inorg. Biochem., 2004, 98, 713-719.

28 L. J. Farrugia, J. Appl. Crystallogr., 1999, 32, 837-838. 